\title{
Hematotoxic Snakebite Victim with Trauma: The Role of Guided Transfusion, Rotational Thromboelastometry, and Tranexamic Acid
}

\author{
Siju V. Abraham, MD ${ }^{1}$; Bezalel Hakkeem, $\mathrm{MBBS}^{1}$; Deo Mathew, $\mathrm{MD}^{1}$; Aboobacker Mohamed Rafi, MD ${ }^{2}$; \\ Aruvi Poomali, $\mathrm{MD}^{3}$; Joe Thomas, $\mathrm{MD}^{4}$; C.K. Kassyap, $\mathrm{MD}^{1}$ \\ ${ }^{1}$ Department of Emergency Medicine, Jubilee Mission Medical College and Research Institute, Thrissur, Kerala, India; ${ }^{2}$ Department of Transfusion Med- \\ icine, Jubilee Mission Medical College and Research Institute, Thrissur, Kerala, India; ${ }^{3}$ Department of Pharmacology, DM Wayanad Institute of Medical \\ Sciences, Wayanad, Kerala, India; ${ }^{4}$ Department of General Medicine, Jubilee Mission Medical College and Research Institute, Thrissur, Kerala, India
}

\begin{abstract}
Hematotoxic snake bite is a leading cause of mortality in South India. However, it is rare for the emergency physician to encounter a patient with trauma associated with snakebite. Management of such a patient differs substantially from the routine management of either a trauma patient or a snakebite victim. A 59-y-old man was bitten by a snake, after which he lost consciousness, fell, and sustained facial trauma. He was rushed to the emergency department within $30 \mathrm{~min}$ and was discovered to have ongoing oromaxillofacial bleeding. His respiratory distress and gasping respirations warranted orotracheal intubation and ventilation. He was treated with anti-snake venom and underwent viscoelastometry-guided transfusion to correct coagulopathy. Hemostasis was achieved after administration of tranexamic acid and bilateral posterior nasal packing. Imaging studies revealed craniomaxillofacial trauma with intracranial hemorrhage. He underwent a delayed mandibular repair. Judicious, guided fluid management, adequate nutrition, and prompt weaning off the ventilator allowed early discharge of the patient from the hospital. The minimal weakness present in his left lower limb at the time of discharge had improved by the time of follow-up. This report shows the utility of early and rapid anti-snake venom in envenomated victims with coagulopathy. The role of cryoprecipitate, tranexamic acid, and viscoelastometric testing needs further exploration in specific hematotoxic snakebites.
\end{abstract}

Keywords: coagulopathy, viscoelastometry, antivenom

\section{Introduction}

In recent years, snakebite has been gaining recognition as a "disease." ${ }^{1}$ In developing countries, the management of snakebite victims is governed by cost-effective strategies. Even though snakebite has been comprehensively discussed in the literature, cases with concurrent complications such as trauma are seldom addressed. Such complicated cases occur largely in the rural setting. Consequently, the eventual morbidity and mortality are not reported. ${ }^{2,3}$ The

Corresponding author: Siju V. Abraham, MD, Department of Emergency Medicine, Jubilee Mission PO, Jubilee Mission Medical College and Research Institute, Thrissur, Kerala, India; e-mail: sijuvabraham@gmail.com.

Submitted for publication May 2020.

Accepted for publication August 2020. scarcity of literature on the subject and the lack of availability of evidence-based guidelines result in varying practices in the use of anti-snake venom (ASV) and blood product in treating snakebite. 4,5

Through this case report, we intend to review the evidence behind rapid administration of ASV and blood products, the rapid correction of coagulopathy, the role of global coagulation assays, and use of tranexamic acid (TXA) in snakebite victims with concurrent trauma and coagulopathy.

\section{Case Report}

A 59-y-old man was brought to the emergency department after snakebite. He was bitten on his feet at 0800 while walking through a bushy area (Figure 1A). The 


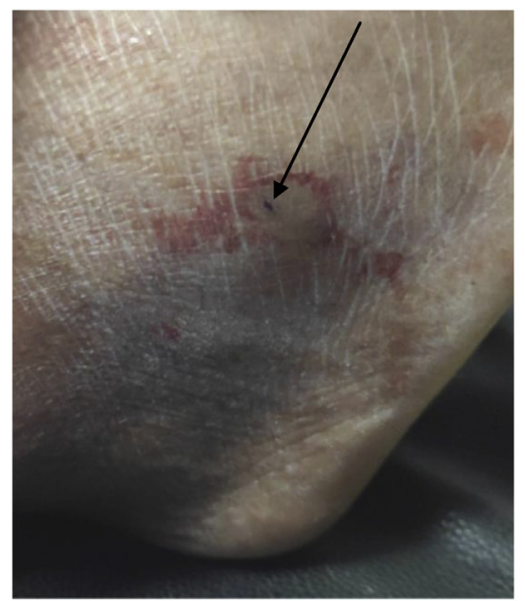

$\mathbf{A}$

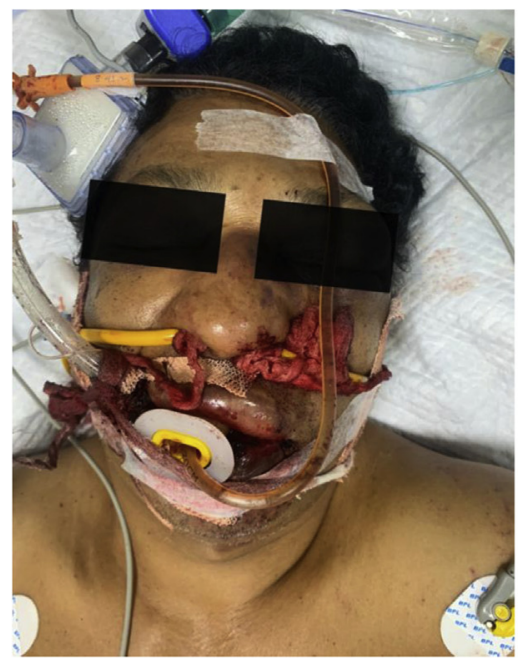

D

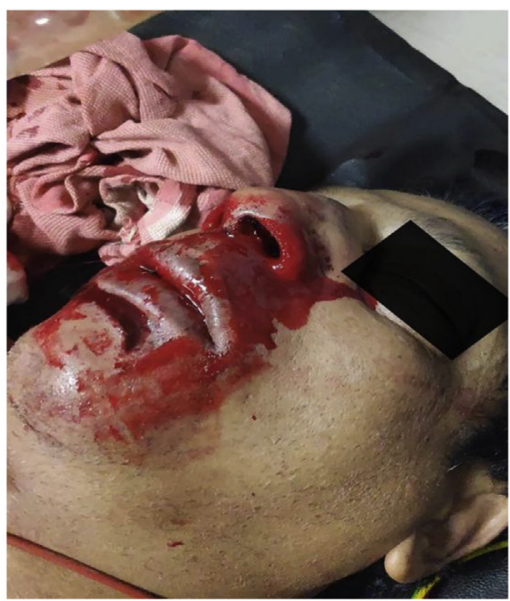

B

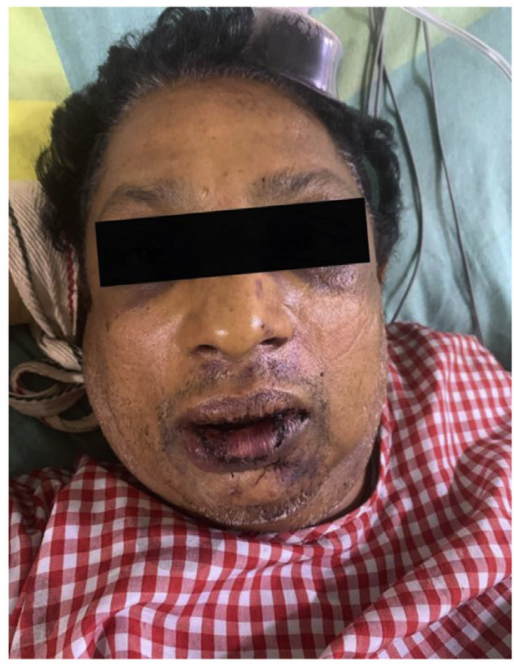

$\mathbf{E}$

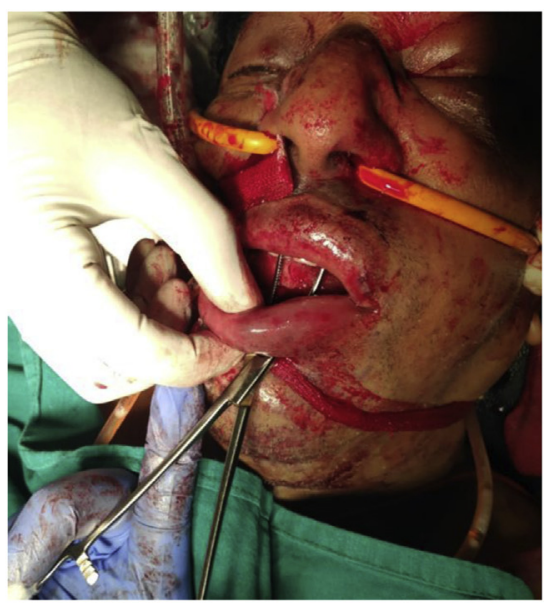

C

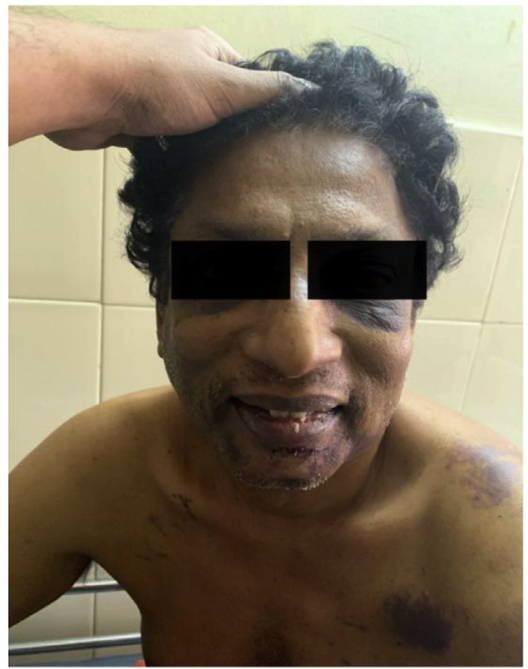

F

Figure 1. Clinical images. (A) Bite mark noted over the lateral aspect of the right foot with a subtle ecchymotic patch toward the heel (arrow mark pointing at the puncture wound). (B) At admission he was gasping, with severe oromaxillofacial bleeding and a Glasgow Coma Scale score of 4E1V2M1. (C) After intubation: bilateral posterior nasal packing done with Foley catheter. Through and through lacerated wound on the lower jaw with ongoing bleed sutured soon after. (D) Two hours later, coagulopathy improved, with no active hemorrhage. (E) After extubation: confused, but obeying commands. No coagulopathy. (F) Conscious and well oriented. Multiple contusions present over the body, now resolving.

culprit snake was never identified. His wife, who was with him at the time, witnessed him lose consciousness within 5 min after the bite and fall into a pit nearly 1.5 m deep.

At 0830, he was brought to the emergency department gasping, with severe bleeding from the mouth and nose impeding normal respiratory efforts. This warranted drugassisted orotracheal intubation (Figure 1B). A laceration on the lower jaw, chemosis, and purpuric contusions over his left shoulder were noted.

At 0840, polyvalent ASV was started (10 vials) as per the department hematotoxic envenomation protocol
(Figure 2). Breathing and ventilation was optimized, but pulsatile bleeding from the nose continued and could not be controlled with direct pressure or cold compress. The initial blood sample drawn showed features suggestive of consumptive coagulopathy (prothrombin time $>180 \mathrm{~s}$ [normal 10-14 s]; activated partial thromboplastin time $>180 \mathrm{~s}$ [normal $25-35 \mathrm{~s}$ ], serum fibrinogen $<10 \mathrm{mg} \cdot \mathrm{dL}^{-1}$ [normal $\left.200-400 \mathrm{mg} \cdot \mathrm{dL}^{-1}\right]$ ) with normal liver and renal function. Rotational thromboelastometry (ROTEM) showed no clot formation (Figure 3A).

At 0855, with the first dose of ASV complete, a persistent tendency to bleed was noted; hence, the 


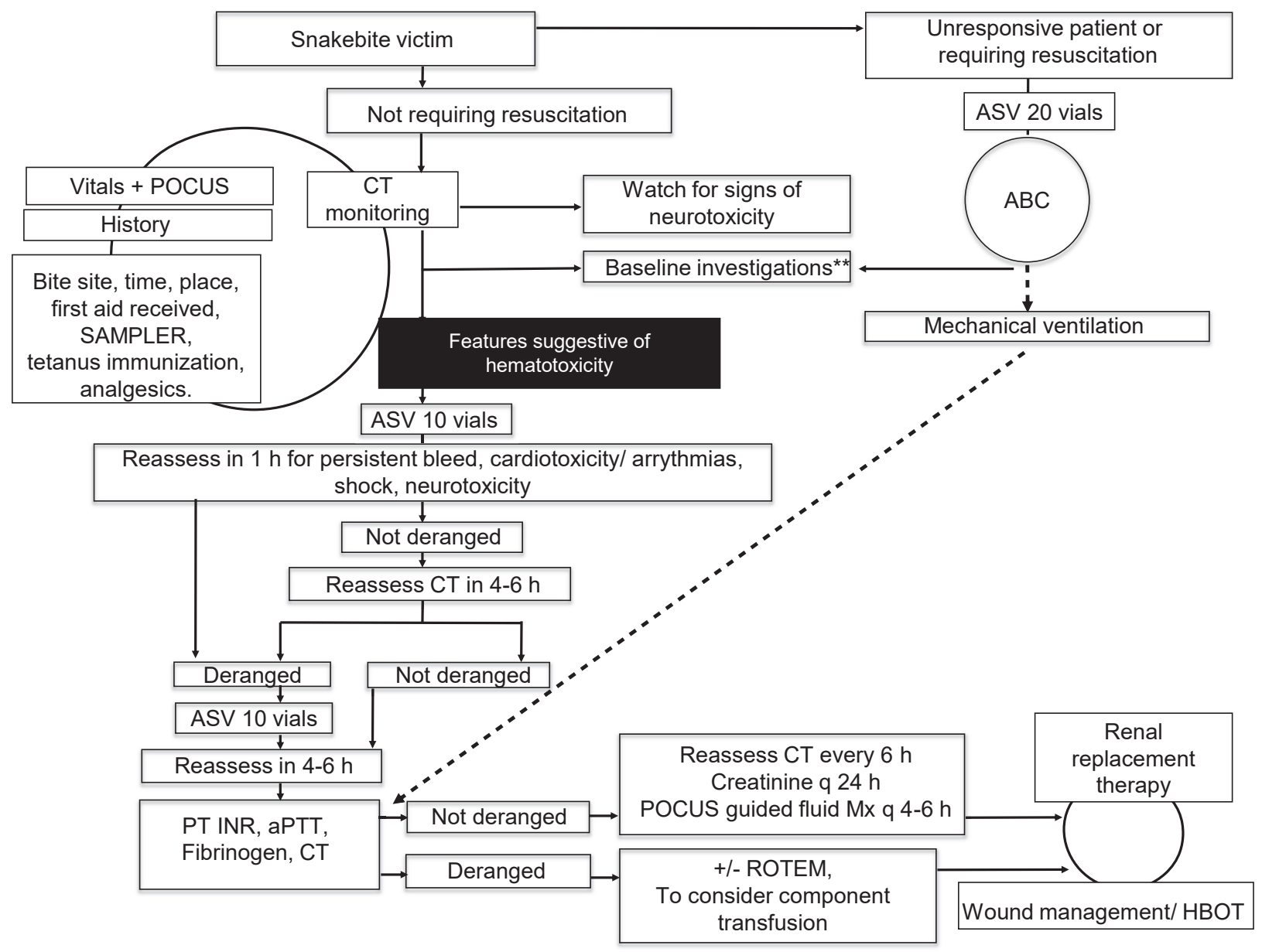

Figure 2. Institute $\left(\mathrm{JMH} \mathrm{ED}^{a}\right)$ snakebite management protocol. aPTT, activated partial thromboplastin time; ABC, airway, breathing, and circulation; ASV, anti-snake venom; CT, clotting time (modified Lee and White test); CBC, complete blood count; HBOT, hyperbaric oxygen therapy; INR, international normalized ratio; JMH ED, Jubilee Mission Hospital Emergency Department; Mx, management; POCUS, point of care ultrasound; PT, prothrombin time; ROTEM, rotational thromboelastometry; SAMPLER, signs and symptoms, allergies, medications, past medical history, last meal, events leading to the present illness, and risk factors. Baseline investigations include complete blood count, creatinine, PT INR, aPTT. Additional blood tests are sent at admission as per the discretion of the treating clinician on a case by case basis. ${ }^{a}$ JMH ED protocol reproduced with permission.

second dose of ASV (10 vials) was started in congruence with the protocol and was administered over the next $15 \mathrm{~min}$.

On reassessment at 0915, the patient had ongoing maxillofacial bleed. Point of care ultrasound showed a hyperdynamic heart with an exaggerated phasic variation of inferior vena cava with respiration, warranting fluid replacement. One unit of O-negative packed red blood cells was commenced, along with 3 units of fresh frozen plasma (FFP) to partially compensate for the volume loss, correct coagulopathy, and improve tissue oxygenation. Crystalloid or colloid transfusions were strictly restricted. He was also given $1 \mathrm{~g}$ of TXA and 10 units of cryoprecipitate.

On repeat ROTEM, clot formation was seen but with a slightly prolonged $\mathrm{CT}_{\text {EXTEM }}$ and $\mathrm{CT}_{\text {FIBTEM }}$ (Figure $3 \mathrm{~B}$ ).
The laceration on the lower jaw was sutured. A Foley catheter was inserted through each nostril and bulb inflated with air to achieve hemorrhage control (Figure 1C).

By 0930, the decision was made to stop further transfusion because clinically the bleed had decreased, and ROTEM findings were reassuring (Figure 3B).

Computed tomography imaging of the head revealed a thin intraventricular hemorrhage, right subcondylar mandibular fracture with temporomandibular dislocation, and left maxillary sinus fractures in the anterior and posterior walls with pneumo-orbit on the same side (Figure 4). Computed tomography imaging of the chest showed consolidated right lower lung zones with thin pleural effusion. Following this, the patient was transferred to the medical intensive care unit (Figure 1D) 
3A

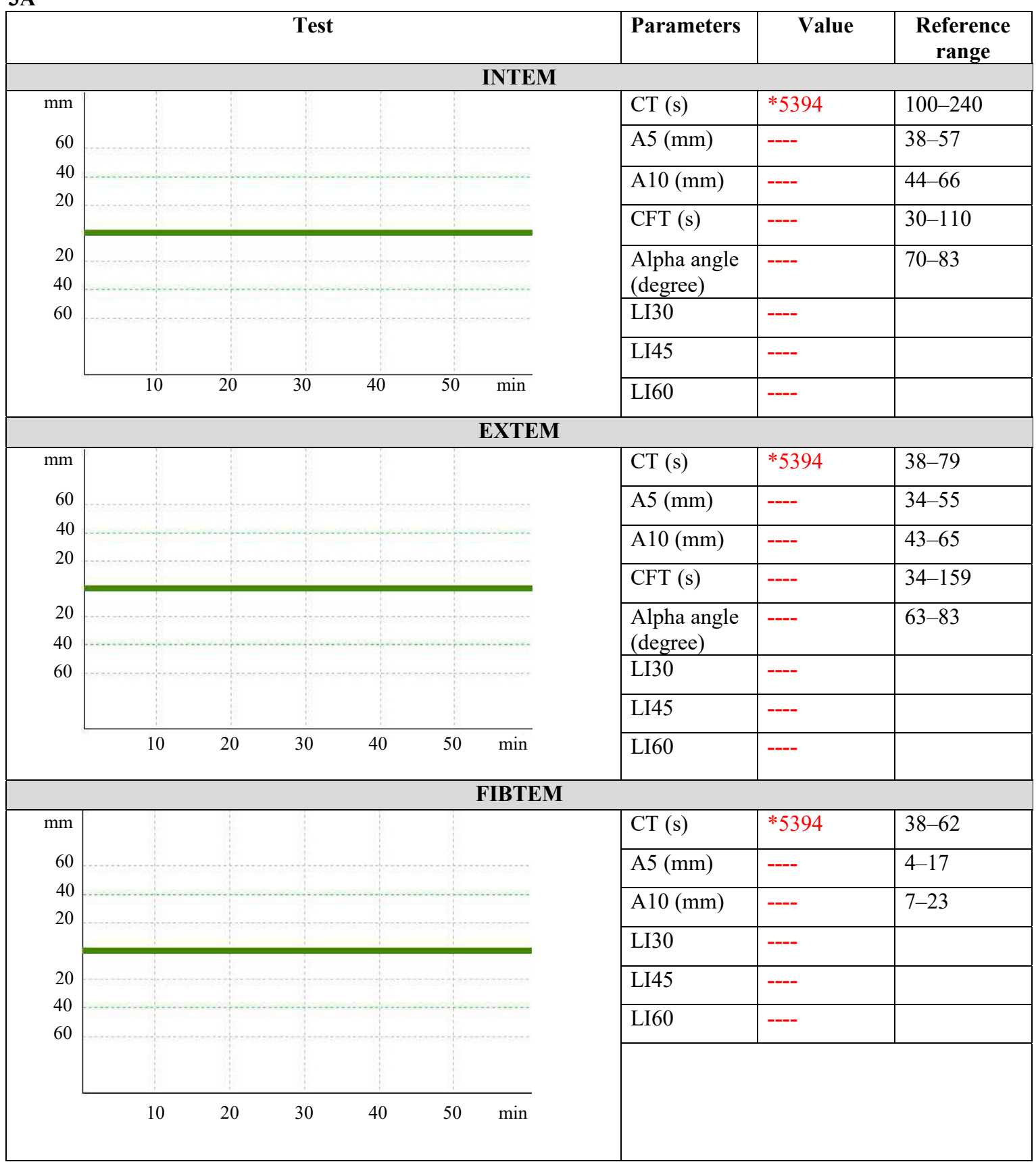

Figure 3. Serial ROTEM. (A) ROTEM at presentation (sample time: 0835) $\mathrm{CT}_{\text {EXTEM, }} \mathrm{CT}_{\text {INTEM }}$ and $\mathrm{CT}_{\mathrm{FIBTEM}}$ showing no clot formation. (B) ROTEM after 20 vials of ASV, 10 units cryoprecipitate, and 1 unit of packed red blood cell transfusion (sample time: 0920) showed clot formation, with CT EXTEM $_{\text {and }}$ $\mathrm{CT}_{\text {FIBTEM }}$ slightly prolonged with a lysis index at $60 \mathrm{~min}, 95 \%$. (C) ROTEM after blood transfusion and tranexamic acid injection (sample time:1035) showed normal clot formation, with no lysis of clot. Three ROTEM tests were performed: extrinsically activated assay with tissue factor (EXTEM), intrinsically activated test using kaolin (INTEM), and extrinsically activated test with tissue factor and the platelet inhibitor cytochalasin D (FIBTEM). For the ROTEM assays, the following variables were measured: clotting time (CT [s]), time taken from the start of the test to the time for clot until $2 \mathrm{~mm}$ amplitude is reached; alpha angle (alpha) is the angle between the central line and a tangent to the curve through $2 \mathrm{~mm}$ amplitude point, measured in degrees; clot formation time (CFT [s]), time taken for clot of $20 \mathrm{~mm}$ amplitude after CT; A5, A10 (clot amplitude at respective min after the end of CT); and maximum clot firmness (MCF [mm], the maximum amplitude reached during the test). Finally, the lysis index at $60 \mathrm{~min}$ (LI60 [\%], clot firmness 60

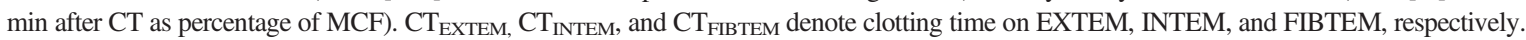


3B

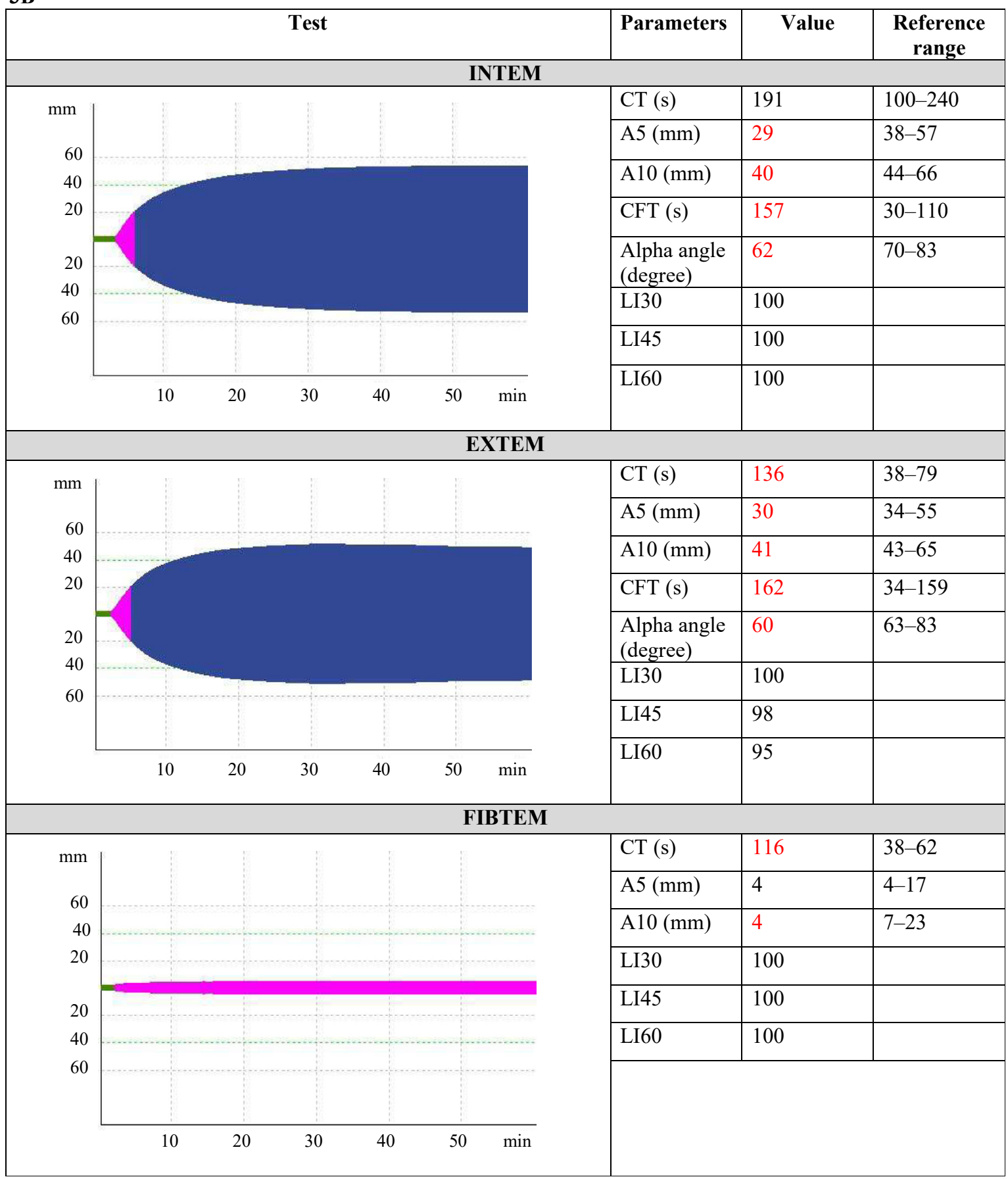

Figure 3. Continued.

where a repeat ROTEM demonstrated a stable clot formation (Figure 3C).

All intravenous fluid was administered, while monitoring his inferior vena cava distensibility (target: $50-80 \%$ ) and hourly urine output. Coagulopathy improved (Tables 1 and 2), and the posterior nasal pack was removed after $12 \mathrm{~h}$. His sensorium improved progressively over the next $24 \mathrm{~h}$ after cessation of sedatives. He was extubated $36 \mathrm{~h}$ after admission (Figure 1E). The dislocated mandibular fracture was fixed $7 \mathrm{~d}$ later, and 
3C

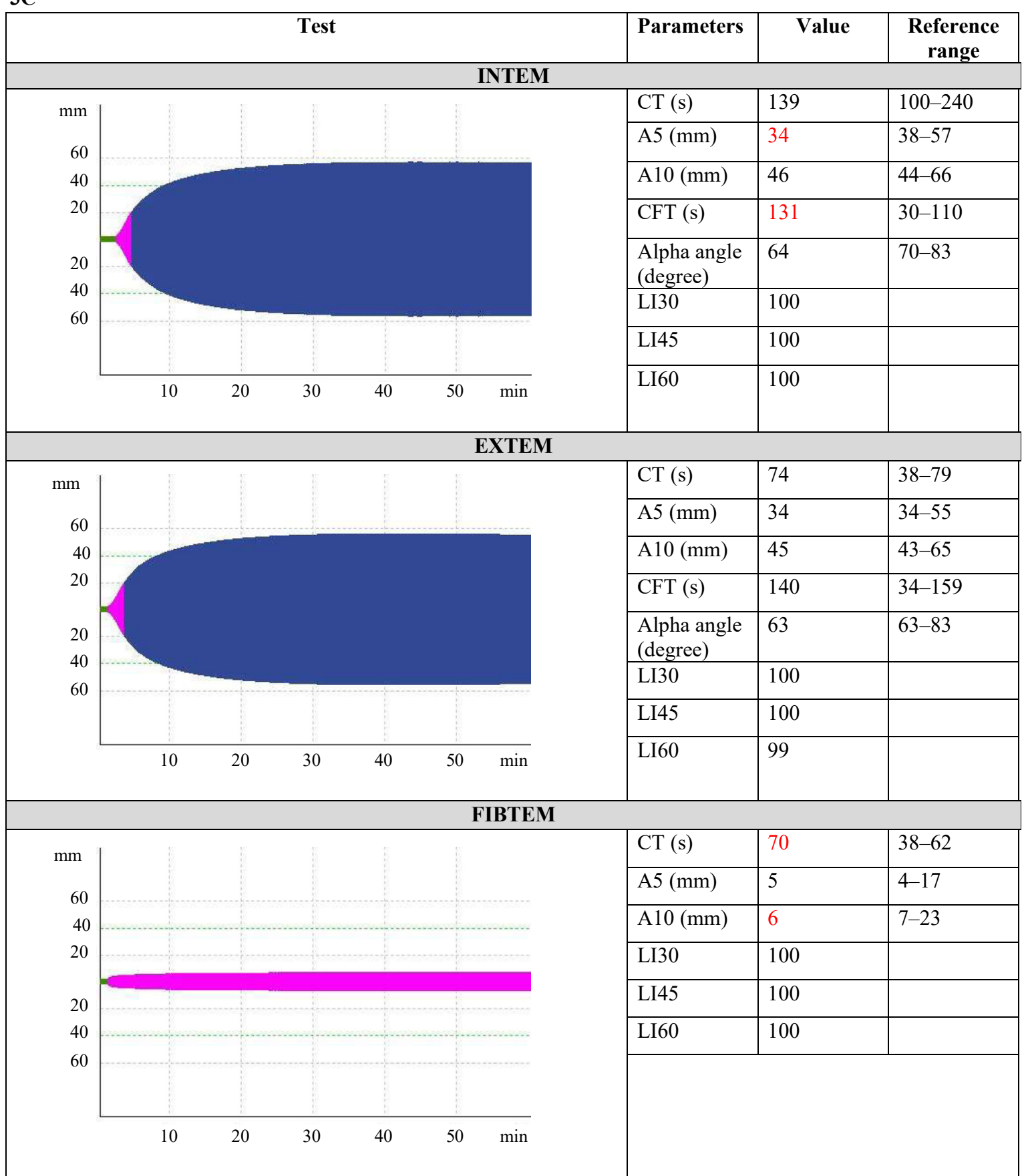

Figure 3. Continued.

intracranial hemorrhage was managed conservatively (Figure 1F). He had residual weakness of his left lower limb, which gradually improved over the course of 1 mo with physical rehabilitation therapy. Modified Rankin score at discharge was 2 , which improved to 0 by the end of 1 mo (Figure 5).

\section{Discussion}

Every year, out of the estimated 138,000 deaths that occur globally due to snake envenomation, 50,000 $(36 \%)$ deaths occur in India. ${ }^{2,3,6,7}$ Snakebite maims less and kills more in India when compared to other 
A

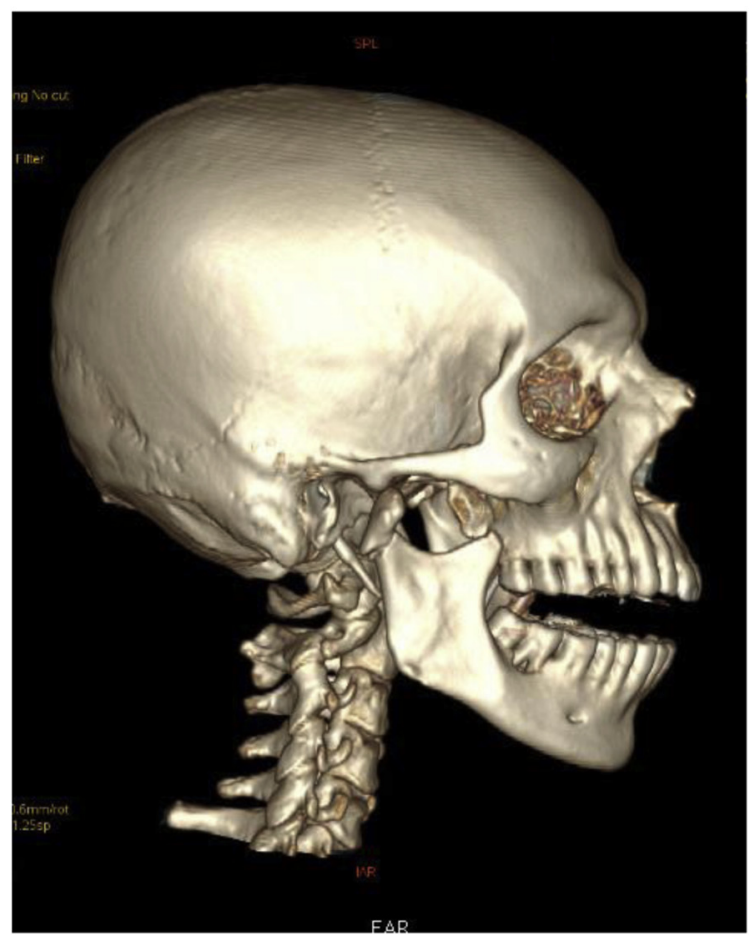

B

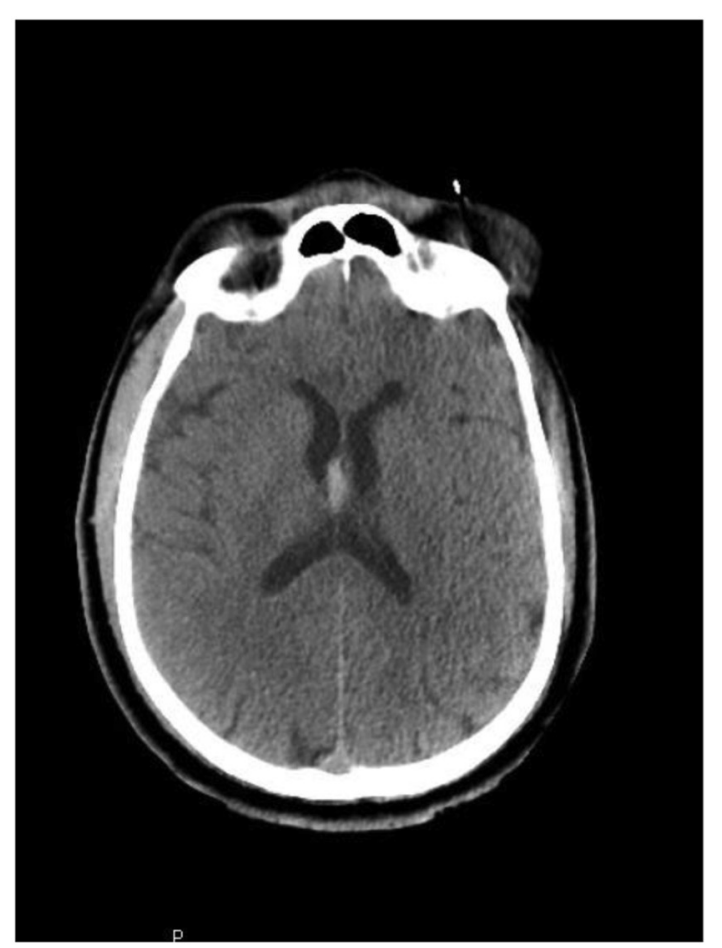

Figure 4. (A) Right subcondylar mandibular fracture with temporomandibular joint dislocation. (B) Axial CT images showing intraventricular hemorrhage. regions in the world. ${ }^{6}$ The most common reason for mortality due to snakebite in South India is coagulopathy, which is also the leading cause of morbid renal failure in the victims. ${ }^{7-9}$ The ASV available in India is polyvalent, capable of neutralizing the venom of Russell's viper (Daboia russelii), binocellate cobra (Naja naja), common krait (Bungarus caeruleus), and saw-scaled viper (Echis carinatus). ${ }^{6}$ In Central Kerala, South India, Russell's viper bites are the most common cause of hematotoxic envenomation, followed by the humpnosed pit viper (Hypnale hypnale). ${ }^{9}{ }^{10}$ Hump-nosed pit viper envenomation in the region has no specific ASV and is notorious for causing prolonged coagulopathy and renal failure. ${ }^{8-11}$

Successful management of snakebite victims with coagulopathy lies in achieving hemostasis and effective nephroprotection. ${ }^{12}$ Venom-induced consumptive coagulopathy (VICC) and early trauma-induced coagulopathy (ETIC) are a spectrum of disorders that span hypo- and hypercoagulable states, ultimately causing depletion of the coagulation cascade and resulting in clinical bleed. ${ }^{13,14}$ VICC is often described as differing from disseminated intravascular coagulation (DIC), especially in its rapidity of setting and resolution. ${ }^{15}$ In a patient with trauma after snakebite, the target should be to minimize the clinical bleed in the individual. We suggest the following strategies employed in the case management of a hematotoxic snake envenomation with concurrent trauma.

\section{EARLY, RAPID ASV}

Rapid administration of ASV is controversial, especially because of the antigenic potential of the equine-derived polyvalent ASV in the region. ${ }^{16}$ Rapid infusion of ASV (in $20 \mathrm{~min}$ ) has been shown not to affect the incidence or severity of early ASV reactions compared to slow infusions (over $120 \mathrm{~min}$ ). ${ }^{17}$

The practicing clinician should keep 2 points in mind in this context to guide judgment:

1. The ASV needs to be administered in its full dose even in a patient with severe anaphylaxis. ${ }^{18}$

2. The earlier the ASV is in the system, the earlier the weight-to-weight binding of venom to ASV occurs, minimizing systemic damage. ${ }^{19-22}$

We administered the standard dose of ASV (10 vials) over a period of $15 \mathrm{~min}$ and a second dose in another 10 to $15 \mathrm{~min}$, keeping in mind to watch for early anaphylaxis and delayed serum sickness. 
Table 1. Blood investigations (Day 1)

\begin{tabular}{|c|c|c|c|c|c|}
\hline \multirow[t]{2}{*}{ Investigations } & \multirow[t]{2}{*}{ Reference range ${ }^{a}$} & \multicolumn{4}{|c|}{ Day 1 sampling time } \\
\hline & & 0830 & 0920 & 1430 & 2030 \\
\hline Hemoglobin $\left(\mathrm{g} \cdot \mathrm{dL}^{-1}\right)$ & $14-16$ & 15.3 & 12.9 & $b$ & 10 \\
\hline Hematocrit $(\%)$ & $40-54$ & 49.8 & 40.2 & $b$ & 31.1 \\
\hline Total count $\left(\mathrm{mm}^{-3}\right)$ & $4000-11,000$ & 12240 & 9720 & $b$ & 9250 \\
\hline Platelets $\left(\mu \mathrm{L}^{-1}\right)$ & $150,000-400,000$ & 145,000 & 240,000 & $b$ & 164,000 \\
\hline $\begin{array}{l}\text { Clotting time (modified Lee } \\
\text { and White method [min]) }\end{array}$ & $10-20$ & $>30$ & $b$ & 18 & 14 \\
\hline PT (s) & $10-14$ & $>180(\mathrm{ctrl}: 13.8)$ & $25.70(\mathrm{ctrl}: 13.8)$ & $17.4(\mathrm{ctrl}: 13.8)$ & $13.2(\mathrm{ctrl}: 12.1)$ \\
\hline APTT (s) & $25-35$ & $>180(\operatorname{ctrl}: 31)$ & $35.7(\operatorname{ctrl}: 31)$ & $23.5(\mathrm{ctrl}: 31)$ & $23.4(\mathrm{ctrl}: 30)$ \\
\hline INR & $0.96-1.32$ & $>18$ & 1.93 & 1.28 & 1.09 \\
\hline Fibrinogen $\left(\mathrm{mg} \cdot \mathrm{dL}^{-1}\right)$ & $200-400$ & $<10$ & $b$ & 168 & 245 \\
\hline LDH (units $\mathrm{L}^{-1}$ ) & $120-246$ & 511 & $b$ & $b$ & $\bar{b}$ \\
\hline
\end{tabular}

APTT, activated partial thromboplastin time; ctrl, control; INR, international normalized ratio; LDH, lactate dehydrogenase; PT, prothrombin time.

${ }^{a}$ Reference values are affected by many variables, including the patient population and the laboratory methods used. The ranges used at Jubilee Mission Medical College \& Research Institute are for adults who do not have medical conditions that could affect the results. They may therefore not be appropriate for all patients.

${ }^{b}$ Investigation not done or result unavailable.

\section{ROLE OF EARLY TRANSFUSION}

The firmness or strength of the clot formed aids in stopping the bleed. The stable fibrin mesh formation at the end of the cascade with platelets determines the clot strength. ${ }^{23}$

In snakebite victims, the cascade is triggered at multiple levels, leading to consumption of coagulation factors. The fibrinolytic enzymes in the venom concurrently result in dissolution of a formed clot. ${ }^{14,15}$ Supplementing the coagulation factors in the form of plasma is often theorized to worsen VICC if the venom is not already neutralized by $\mathrm{ASV} .{ }^{24}$ On the other hand, although ASV is widely recommended for VICC, researchers claim there is limited evidence to support its effectiveness. ${ }^{25}$ Plasma transfusion may improve the laboratory parameters in snakebite victims, although its benefits in reducing mortality and morbidity are still under scrutiny. ${ }^{5,14,26,27}$

In our patient, the ASV was infused in less than $30 \mathrm{~min}$, and we tested the patient's blood again for any signs of improvement in coagulopathy. With no signs of stable clot formation in the patient and in view of his ongoing maxillofacial bleed, we proceeded with early transfusion.

Table 2. Blood investigations (Days 2-13)

\begin{tabular}{|c|c|c|c|c|c|c|c|}
\hline Investigations & Reference range ${ }^{a}$ & Day 2 & Day 3 & Day 4 & Day 5 & Day 6 & Day 13 \\
\hline Hemoglobin $\left(\mathrm{g} \cdot \mathrm{dL}^{-1}\right)$ & $14-16$ & 8 & 8.9 & 9.4 & 11.2 & 12.2 & 11.8 \\
\hline Hematocrit $(\%)$ & $40-54$ & 24 & 27.8 & $b$ & & $b$ & 38 \\
\hline Platelets $\left(\mu \mathrm{L}^{-1}\right)$ & $150,000-400,000$ & 159,000 & 224,000 & 215,000 & 235,000 & 265,000 & $b$ \\
\hline Bleeding time $(\mathrm{min})$ & $3-6$ & 4 & $b$ & $b$ & $b$ & $b$ & $b$ \\
\hline $\begin{array}{l}\text { Clotting time }- \text { modified Lee } \\
\text { and White method (min) }\end{array}$ & $10-20$ & 14 & $b$ & 13 & $b$ & $b$ & $b$ \\
\hline $\mathrm{PT}(\mathrm{s})$ & $10-14$ & $13.7(\mathrm{ctrl}: 12.1)$ & $12.3(\mathrm{ctrl}: 12.1)$ & $b$ & $b$ & $b$ & $b$ \\
\hline APTT (s) & $25-35$ & $23.5(\operatorname{ctrl}: 30)$ & $25(\operatorname{ctrl}: 30)$ & $b$ & $b$ & $b$ & $b$ \\
\hline INR & $0.96-1.32$ & 1.13 & 1.02 & $b$ & $b$ & $b$ & $b$ \\
\hline Fibrinogen $\left(\mathrm{mg} \cdot \mathrm{dL}^{-1}\right)$ & $200-400$ & 511 & 406 & $b$ & $b$ & $b$ & $b$ \\
\hline Creatinine $\left(\mathrm{mg} \cdot \mathrm{dL}^{-1}\right)$ & $0.52-1.1$ & 0.9 & 1.1 & 1.1 & 1.1 & 0.9 & 1 \\
\hline
\end{tabular}

APTT, activated partial thromboplastin time; ctrl, control; INR, international normalized ratio; PT, prothrombin time.

${ }^{a}$ Reference values are affected by many variables, including the patient population and the laboratory methods used. The ranges used at Jubilee Mission Medical College \& Research Institute are for adults who do not have medical conditions that could affect the results. They may therefore not be appropriate for all patients.

${ }^{b}$ Investigation not done or result unavailable. 


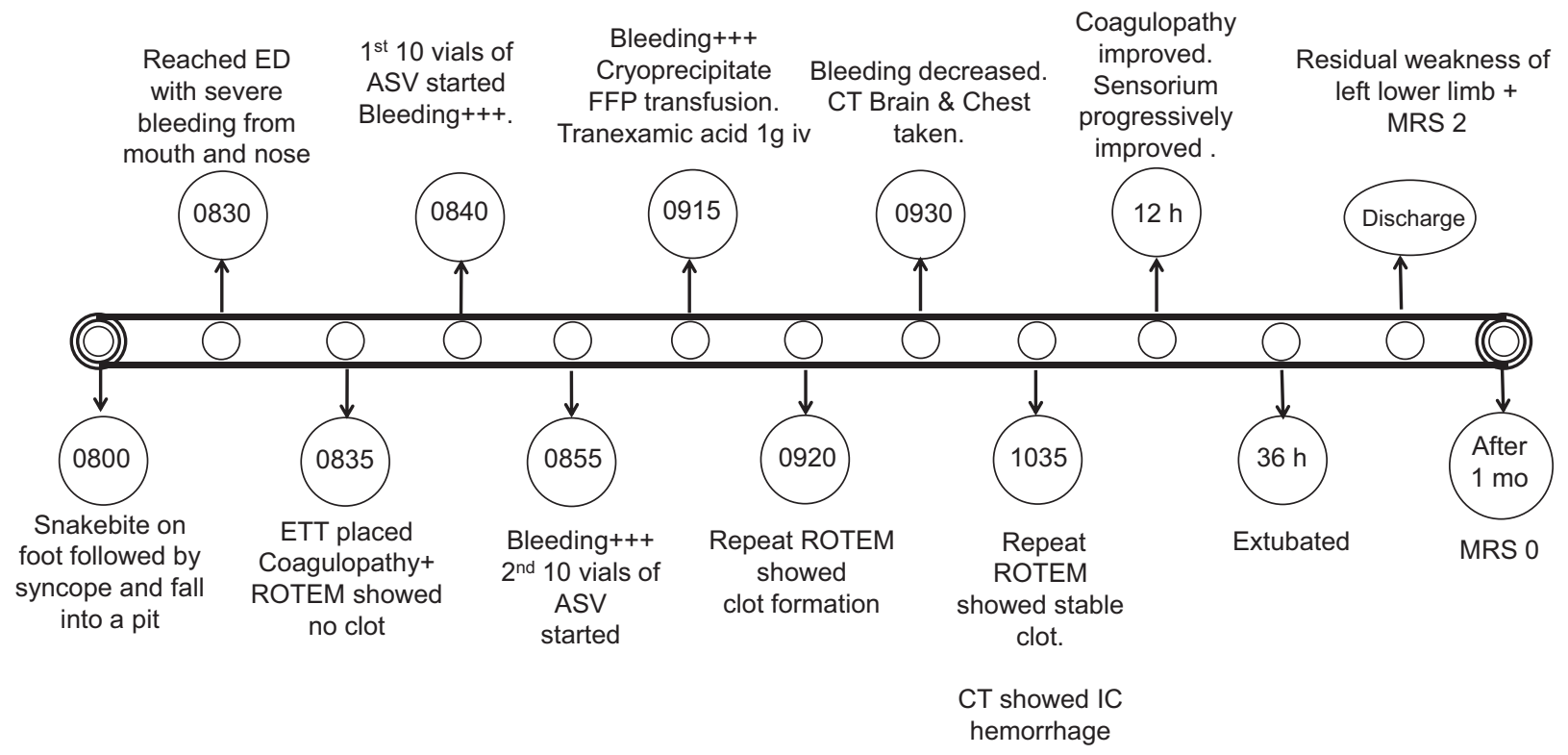

Figure 5. Timeline of events. CT, computed tomography; ED, emergency department; ETT, endotracheal tube; FFP, fresh frozen plasma; IC, intracranial; MRS, modified rankin score; ROTEM, rotational thromboelastometry.

\section{ROLE OF CRYOPRECIPITATE TRANSFUSION}

The ROTEM-guided algorithm supported administration of fibrinogen concentrate or cryoprecipitate over plasma in trauma to improve clot firmness; in the event of massive hemorrhage, clot firmness is affected before thrombin generation. $^{28}$

In our case, because blood loss was mostly due to coagulopathy, we decided to replace fibrinogen as we would in trauma, but with restricted fluids to minimize overload and strain of the kidneys.

The venom of both Daboia russelii and Hypnale hypnale is notorious for causing depletion of fibrinogen. ${ }^{14,21}$ Hypnale envenomation also causes factor VIII deficiency. ${ }^{21,29}$ ETIC also causes fibrinogen depletion. ${ }^{30}$ Cryoprecipitate contains less volume than plasma and is a more concentrated source of fibrinogen and factor VIIII. ${ }^{31}$ Hence, we preferred it over FFP as our first blood component in a setting of coagulopathy in a snakebite victim with head trauma.

\section{ROLE OF PACKED RED BLOOD CELLS IN COAGULOPATHY}

The role of red blood cells (RBCs) in achieving hemostasis and their prothrombotic properties are often given less importance by the clinician in comparison to other blood products, such as FFP. ${ }^{32}$ The rheological effects of RBCs include their being concentrated in the center of blood vessels, with consequent platelet-rich plasma margination to the vessel wall. ${ }^{33}$ RBCs interact with endothelial cells, platelets, and fibrinogen and affect the structure and mechanical properties of clots, aiding in clot stabilization. ${ }^{34}$ RBC volume correction should occur concurrently in the management of bleeding patient to improve hemostasis. ${ }^{35}$

\section{ROLE OF ROTEM-GUIDED TRANSFUSION IN HEMATOTOXIC ENVENOMATION}

The traditional coagulation tests (prothrombin time, activated partial thromboplastin time) have been standardized for monitoring therapy in vitro. They inform on the initiation of clotting but may not reflect the hemostatic capacity of the individual in vivo. Global coagulation assays such as viscoelastometric tests (eg, ROTEM, thromboelastogram) or clot waveform analysis look beyond the initiation of coagulation and provide global information on the dynamics of clot development, stabilization, and dissolution that closely reflects hemostasis in vivo. ${ }^{28,36}$

In our patient, the ROTEM at admission showed no clot formation, whereas the one soon after transfusion showed stable clot formation, which was mirrored by clinical resolution of bleed in the victim (Figure 3). Viscoelastometric tests aid in tailoring transfusion according to patient status in ETIC. ${ }^{37}$ Its role in snakebite management is limited to case series and case reports. ${ }^{38-43}$ Fibrinogen depletion that occurs in ETIC is associated with a prolonged $\mathrm{CT}_{\text {EXTEM }}$ assay. ${ }^{30}$

One key aspect of interest in interpreting the results of ROTEM in trauma victims is that they should be in a reasonable sequence ( $\mathrm{A} 5_{\text {FIBTEM }}$ prior to $\mathrm{CT}_{\text {EXTEM }}$ ), not according to availability $\left(\mathrm{CT}_{\text {EXTEM }}\right.$ prior to $\left.\mathrm{A} 5_{\text {FIBTEM }}\right){ }^{28,37}$ There is also a need to study the results of ROTEM in a 
snakebite victim to identify its usefulness (in guiding therapy) while avoiding the potential for misinterpretation of the results.

\section{ROLE OF TRANEXAMIC ACID IN SNAKEBITE}

Fibrinolytic enzymes in snake bite cause dissolution of the formed clot, as evidenced by clot lysis in vitro. ${ }^{44}$ Hence, antifibrinolytic drugs have been used in the management of snakebite victims by some. ${ }^{45,46}$

Microthrombi formed in DIC are shown to lead to end organ damage, as evidenced most commonly by acute tubular necrosis and renal failure. ${ }^{47}$ The possibility of thrombotic microangiopathy in bite victims and impaired clearing of microthrombi in renal vasculature leading to renal failure is an argument against the use of antifibrinolytics such as TXA. ${ }^{48,49}$ In the early phase, DIC is prothrombotic; it then progresses to a hyperfibrinolytic phase and later enters an antifibrinolytic state ${ }^{50,51}$ The coagulopathic changes in a snakebite victim happen in a matter of minutes to hours. ${ }^{36}$ TXA might have a role in the hyperfibrinolytic phase. Once renal failure sets in, administering TXA could be more harmful because it is dependent on the renal excretion pathway. ${ }^{52}$

In our patient with evident ongoing hemorrhage, we administered TXA as a stat dose earlier on. No rise in serum creatinine or decrease in urine output was noted throughout the patient's hospital stay in our institute. Stringent fluid management and nutritional support were emphasized throughout the management of the victim.

In snakebite, the role of TXA and the timeframe in which it needs to be administered can be challenging because the venom profile and its effect on the coagulation pathway vary among the various snakes seen in this region. ${ }^{53}$ Researchers should prospectively take the lead to identify TXA's potential use in snakebite victim management.

\section{Conclusions}

Concurrent administration of ASV and blood products, rapid correction of coagulopathy, and the roles of TXA and viscoelastometric testing are all areas of controversy in the management of snake envenomation and trauma victims. Early and rapid ASV administration is to be considered in envenomated victims with coagulopathy. The role of cryoprecipitate and TXA in specific hematotoxic snakebites needs to be further explored. Even if viscoelastometric tests may not be cost-efficient screening tests, they might have a role in guiding transfusion requirements in patients with coagulopathy after envenomation.
Acknowledgments: The authors acknowledge the contribution of Dr Paul Mathai, from the Department of Oromaxillofacial Surgery, for his help in patient care.

Author Contributions: SVA, DM, JT, and KCK were involved in the patient care. SVA reviewed the literature and wrote the first draft. $\mathrm{BH}$ and DM were responsible for the infographics and compilation of the figures and legends. AP, SVA, DM, AMR, JT, BH, and KCK reviewed the manuscript and approved it.

Financial/Material Support: None.

Disclosures: None.

\section{References}

1. Chippaux JP. Snakebite envenomation turns again into a neglected tropical disease!. J Venom Anim Toxins Trop Dis. 2017;23:38.

2. Chippaux JP. Snake-bites: appraisal of the global situation. Bull World Health Organ. 1998;76(5):515-24.

3. Mohapatra B, Warrell DA, Suraweera W, Bhatia P, Dhingra N, Jotkar RM, et al. Snakebite mortality in India: a nationally representative mortality survey. PLoS Negl Trop Dis. 2011;5(4):e1018.

4. Das RR, Sankar J, Dev N. High-dose versus low-dose antivenom in the treatment of poisonous snake bites: a systematic review. Indian J Crit Care Med. 2015;19(6): 340-9.

5. Holla SK, Rao HA, Shenoy D, Boloor A, Boyanagari M. The role of fresh frozen plasma in reducing the volume of antisnake venom in snakebite envenomation. Trop Doct. 2018;48(2):89-93.

6. Alirol E, Sharma SK, Bawaskar HS, Kuch U, Chappuis F. Snake bite in South Asia: a review. PLoS Negl Trop Dis. 2010;4(1), e603.

7. Menon JC, Joseph JK, Whitaker RE. Venomous snake bite in India - why do 50,000 Indians die every year? J Assoc Physicians India. 2017;65(8):78-81.

8. Suchithra N, Pappachan JM, Sujathan P. Snakebite envenoming in Kerala, South India: clinical profile and factors involved in adverse outcomes. Emerg Med J. 2008;25(4): 200-4.

9. Menon JC, Joseph JK, Jose MP, Dhananjaya BL, Oommen OV. Clinical profile and laboratory parameters in 1051 Victims of snakebite from a single centre in Kerala, South India. J Assoc Physicians India. 2016;64(8):22-9.

10. Kumar KS, Narayanan S, Udayabhaskaran V, Thulaseedharan NK. Clinical and epidemiologic profile and predictors of outcome of poisonous snake bites - an analysis of 1,500 cases from a tertiary care center in Malabar, North Kerala, India. Int J Gen Med. 2018;11:209-16.

11. Abraham SV. Snake bite in India: a few matters to note. Toxicol Rep. 2018;5:839.

12. Jayakumar M, Prabahar MR, Fernando EM, Manorajan R, Venkatraman R, Balaraman V. Epidemiologic trend changes in acute renal failure - a tertiary center experience from South India. Ren Fail. 2006;28(5):405-10.

13. Chang R, Cardenas JC, Wade CE, Holcomb JB. Advances in the understanding of trauma-induced coagulopathy. Blood. 2016;128(8):1043-9. 
14. Maduwage K, Isbister GK. Current treatment for venominduced consumption coagulopathy resulting from snakebite. PLoS Negl Trop Dis. 2014;8(10):e3220.

15. Isbister GK. Snakebite doesn't cause disseminated intravascular coagulation: coagulopathy and thrombotic microangiopathy in snake envenoming. Semin Thromb Hemost. 2010;36(4):444-51.

16. de Silva HA, Ryan NM, de Silva HJ. Adverse reactions to snake antivenom, and their prevention and treatment. $\mathrm{Br} J$ Clin Pharmacol. 2016;81(3):446-52.

17. Isbister GK, Shahmy S, Mohamed F, Abeysinghe C, Karunathilake H, Ariaratnam A. A randomised controlled trial of two infusion rates to decrease reactions to antivenom. PLoS One. 2012;7(6), e38739.

18. Warrell DA. Snake bite. Lancet. 2010;375(9708):77-88.

19. World Health Organization. Guidelines for the Management of Snakebites. 2nd ed. WHO; 2016.

20. Mise YF, Lira-da-Silva RM, Carvalho FM. Time to treatment and severity of snake envenoming in Brazil. Rev Panam Salud Publica. 2018;42:e52.

21. Isbister GK, Maduwage K, Scorgie FE, Shahmy S, Mohamed F, Abeysinghe C, et al. Venom concentrations and clotting factor levels in a prospective cohort of Russell's viper bites with coagulopathy. PLoS Negl Trop Dis. 2015;9(8), e0003968.

22. Rivière G, Choumet V, Audebert F, Sabouraud A, Debray M, Scherrmann JM, et al. Effect of antivenom on venom pharmacokinetics in experimentally envenomed rabbits: toward an optimization of antivenom therapy. J Pharmacol Exp Ther. 1997;281(1):1-8.

23. Levy JH, Szlam F, Tanaka KA, Sniecienski RM. Fibrinogen and hemostasis: a primary hemostatic target for the management of acquired bleeding. Anesth Analg. 2012;114(2): 261-74.

24. White J. Snake venoms and coagulopathy. Toxicon. 2005;45(8):951-67.

25. Maduwage K, Buckley NA, de Silva HJ, Lalloo DG, Isbister GK. Snake antivenom for snake venom induced consumption coagulopathy. Cochrane Database Syst Rev. 2015;6:CD011428.

26. Isbister GK, Jayamanne S, Mohamed F, Dawson AH, Maduwage K, Gawarammana I, et al. A randomized controlled trial of fresh frozen plasma for coagulopathy in Russell's viper (Daboia russelii) envenoming. J Thromb Haemost. 2017;15(4):645-54.

27. Patil S, Paranjape A, Patil NR, Patil HS, Surve RA, Desai MB. Rural set up experience of viper bite treatment with special reference to FFP in venom induced consumption coagulopathy. J Assoc Physicians India. 2019;67(10): $26-8$.

28. Görlinger K, Pérez-Ferrer A, Dirkmann D, Saner F, Maegele M, Calatayud AAP, et al. The role of evidencebased algorithms for rotational thromboelastometry-guided bleeding management. Korean J Anesthesiol. 2019;72(4): 297-322.

29. Maduwage K, Scorgie FE, Silva A, Shahmy S, Mohamed F, Abeysinghe C, et al. Hump-nosed pit viper (Hypnale hypnale) envenoming causes mild coagulopathy with incomplete clotting factor consumption. Clin Toxicol (Phila). 2013;51(7): 527-31.

30. Stensballe J, Henriksen HH, Johansson PI. Early haemorrhage control and management of trauma-induced coagulopathy: the importance of goal-directed therapy. Curr Opin Crit Care. 2017;23(6):503-10.

31. Nascimento B, Goodnough LT, Levy JH. Cryoprecipitate therapy. Br J Anaesth. 2014;113(6):922-34.

32. Weisel JW, Litvinov RI. Red blood cells: the forgotten player in hemostasis and thrombosis. J Thromb Haemost. 2019;17(2):271-82.

33. Flamm MH, Diamond SL. Multiscale systems biology and physics of thrombosis under flow. Ann Biomed Eng. 2012;40(11):2355-64.

34. Wohner N, Sótonyi P, Machovich R, Szabo L, Tenekedjiev K, Silva MMCG, et al. Lytic resistance of fibrin containing red blood cells. Arterioscler Thromb Vasc Biol. 2011;31(10):2306-13.

35. Barshtein G, Ben-Ami R, Yedgar S. Role of red blood cell flow behavior in hemodynamics and hemostasis. Expert Rev Cardiovasc Ther. 2007;5(4):743-52.

36. Abraham SV, Rafi AM, Krishnan SV, Palaty BU, Innah SJ, Johny J, et al. Utility of clot waveform analysis in Russell's viper bite victims with hematotoxicity. J Emerg Trauma Shock. 2018;11(3):211-6.

37. Abdelfattah K, Cripps MW. Thromboelastography and rotational thromboelastometry use in trauma. Int J Surg. 2016;33(Pt B):196-201.

38. Roszko PJD, Kavanaugh MJ, Boese ML, Longwell JJ, Earley AS. Rotational thromboelastometry (ROTEM) guided treatment of an Afghanistan viper envenomation at a NATO military hospital. Clin Toxicol (Phila). 2017;55(3):229-30.

39. Gutiérrez JM, Burnouf T, Harrison RA, Calvete JJ, Kuch U, Warrell DA, et al. A multicomponent strategy to improve the availability of antivenom for treating snakebite envenoming. Bull World Health Organ. 2014;92(7): 526-32.

40. Mullins ME, Freeman WE. Thromboelastometry (ROTEM) and thromboelastography (TEG) in copperhead snakebites: a CASE series. Clin Toxicol (Phila). 2020;58(9):931-4.

41. Leffers P, Ferreira J, Sollee D, Schauben J. Thromboelastography in the management of snakebite-induced coagulopathy: a CASE series and literature review. Blood Coagul Fibrinolysis. 2018;29(7):656-60.

42. Larréché S, Jean FX, Benois A, Mayet A, Bousquet A, Vedy S, et al. Thromboelastographic study of the snakebiterelated coagulopathy in Djibouti. Blood Coagul Fibrinolysis. 2018;29(2):196-204.

43. Hadley GP, McGarr P, Mars M. The role of thromboelastography in the management of children with snake-bite in southern Africa. Trans R Soc Trop Med Hyg. 1999;93(2): 177-9.

44. Benjamin JM, Chippaux JP, Sambo BT, Massougbodji A. Delayed double reading of whole blood clotting test 
(WBCT) results at 20 and 30 minutes enhances diagnosis and treatment of viper envenomation. J Venom Anim Toxins Incl Trop Dis. 2018;24:14.

45. Shah PK, Chittora MD, Vyas MM, Tak RS, Vyas R. Primary pathological fibrinolysis in viper (Echis carinatus) bite treatment by epsilon aminocaproic acid. J Assoc Physicians India. 1987;35(9):654-5.

46. Sapkota S, Acharya RR, Paudel N. Tranexamic acid in patients with green snake bite in western region of Nepal. Birat J Health Sci. 2018;3(1):346-9.

47. Watanabe T, Imamura T, Nakagaki K, Tanaka K. Disseminated intravascular coagulation in autopsy cases. Its incidence and clinicopathologic significance. Pathol Res Pract. 1979;165(3):311-22.

48. Rathnayaka RN, Ranathunga PAN, Kularatne SA. Thrombotic microangiopathy, hemolytic uremic syndrome, and thrombotic thrombocytopenic purpura following Hump-nosed pit viper (Genus: Hypnale) envenoming in Sri Lanka. Wilderness Environ Med. 2019;30(1):66-78.
49. Wijewickrama ES, Gooneratne LV, Gnanathasan A, Gawarammana I, Gunatilake M, Isbister GK. Thrombotic microangiopathy and acute kidney injury following Sri Lankan Daboia russelii and Hypnale species envenoming. Clin Toxicol (Phila).. 2020 [Epub ahead of print].

50. Wada H, Thachil J, Di Nisio M, Mathew P, Kurosawa S, Gando S, et al. Guidance for diagnosis and treatment of DIC from harmonization of the recommendations from three guidelines. J Thromb Haemost. 2013 [Epub ahead of print].

51. Levi M, Sivapalaratnam S. Disseminated intravascular coagulation: an update on pathogenesis and diagnosis. Expert Rev Hematol. 2018;11(8):663-72.

52. McCormack PL. Tranexamic acid: a review of its use in the treatment of hyperfibrinolysis. Drugs. 2012;72(5):585-617.

53. Maduwage KP, Scorgie FE, Lincz LF, O’Leary MA, Isbister GK. Procoagulant snake venoms have differential effects in animal plasmas: implications for antivenom testing in animal models. Thromb Res. 2016;137: 174-7. 